УДК 82.

\author{
МАСКИ БАХЫТА КЕНЖЕЕВА \\ КАК МОДЕЛИРОВАНИЕ ИГРОВЫХ ПОЭТИК
}

\author{
(C) Виктория Арнаутова
}

\title{
BAKHYT KENZHEEV'S MASKS AS A MODEL OF ACTABLE POETICS
}

\begin{abstract}
Viktoria Arnautova
Many researchers note that the mask has been inherent in social and cultural life over the whole period of human existence. Modern scholars suggest many interpretations of this concept, therefore, multiple approaches exist to understanding of the mask. This paper, based on the poems by Bakhyt Kenzheev, considers "the mask" to be a means of forming the author's image in lyrical works. We analyze the classical author's mask as a fictional image with its own biography and poetic system. In the context of Bakhyt Kenzheev's works, we study the ability of the mask to encipher and conceal the author's consciousness. The poet trusts Remont Priborov and the eleven-year-old boy Theodore with the authorship of the "traditionalist" and "patriot" masks, while expanding the boundaries of his work. With the help of masks, Bakhyt Kenzheev creates fictional worlds that are radically different from his usual poetic practices. In this case, a deep satirical image arises, as the face of the true author shows through the mask. The use of the mask is a complex game technique that allows the author to maintain his own identity and expand the boundaries of his work filling it with a new motif.
\end{abstract}

Keywords: author's consciousness, lyrical subject, Bakhyt Kenzheyev, author's mask.

\begin{abstract}
Многие исследователи отмечают, что маска является неотьемлемой частью общественной и культурной жизни на протяжении всего существования человечества. Современные ученые выделяют множество толкований данного понятия и, следовательно, большое количество подходов к осмыслению маски. В статье на материале поэтического творчества Бахыта Кенжеева рассматривается «маска» как средство, формирующее образ автора в лирике. Анализируется классическая авторская маска как художественный образ с собственной биографией и поэтической системой. На примере творчества Бахыта Кенжеева исследуется свойство маски скрывать за собой авторское сознание, зашифровывать его. Поэт доверяет авторство маскам «традиционалисту» и «патриоту» Ремонту Приборову и одиннадцатилетнему мальчику Теодору, при этом расширяя границы своего творчества. Бахыт Кенжеев с помощью масок создает художественные миры, радикально отличающиеся от его привычных поэтических практик. При этом возникает глубокий сатирический образ, так как сквозь данные маски просвечивает лицо истинного автора. Использование маски является сложным игровым приемом, позволяющим автору сохранять собственную идентичность и расширять границы своего творчества, наполняя его новым звучанием.
\end{abstract}

Ключевые слова: авторское сознание, лирический субъект, Бахыт Кенжеев, маска автора.

Многие исследователи отмечают, что маска является неотъемлемой частью общественной и культурной жизни на протяжении всего существования человечества. Современные ученые выделяют множество толкований данного понятия и, следовательно, большое количество подходов к осмыслению маски. Например, Л. В. Левицкая в своей работе подчеркивает, что «тема маски и лица включает множество аспектов: метафизический (лик - лицо - личина), мифотворческий, психологический, социальный (человек в социу- ме: личность - персона), эстетический (маска как образ и как прием в художественном произведении, само произведение как маска автора)» [Левицкая].

Собственно литературная авторская маска определяется как особый прием использования псевдонима, который становится полноценным художественным образом, обретает более или менее развернутую биографию, литературные ориентиры и «собственный голос» [Осьмухина, c. 18]. Несмотря на то что роль литературных ма- 
сок можно свести к двум полярным функциям сокрытие лица и оформление собственной идентичности, в эпических и лирических произведениях маска проявляется по-разному. В лирике, как в самом субъективном из родов литературы, маска тесно связана с авторским сознанием, поэтому цель нашей работы - выяснить роль «маски» в самовыражении автора на примере творчества Б. Ш. Кенжеева (р. 1950).

Бахыта Кенжеева многие критики называют романтическим или даже элегическим поэтом. Тонкий лирик, в своем творчестве он обращается к темам смерти и воскрешения, неумолимого рока, судьбы. Маски «даровитого самородка» Ремонта Приборова и одиннадцатилетнего мальчика Теодора, которые поэт иногда надевает, помогают ему проявить себя в иной поэтической манере.

Формально произведения «традиционалиста» Приборова представляют собой гражданскую лирику, а «модерниста» Теодора - абсурдистские стихотворения, но на тематическом уровне просматриваются определенные параллели с творчеством самого Кенжеева.

Основной вопрос, волнующий автора, - назначение поэта в мире. Посмотрим, как эта традиционная тема раскрывается в творческих парадигмах Приборова, Теодора и самого Кенжеева.

В 1990 году Кенжеев создает стихотворение «Спят мои друзья в голубых гробах. И не видят созвездий, где...», в котором возникает лирический образ поэта, размышляющего о судьбе творца. Произведение состоит из четырех строф и четырех предложений, но их границы не совпадают:

Спят мои друзья в голубых гробах. И не видят созвездий, где

тридцатитрехлетний идет рыбак по волнующейся воде.

За стеной гитарное трень да брень, знать, соседа гнетет тоска.

Я один в дому, и жужжит мигрень зимней мухою у виска,

Я исправно отдал ночной улов перекупщику, и притих,

я не помню, сколько их было, слов, и рифмованных и простых,

и на смену грусти приходит злость - отпусти, я кричу, не мучь -

но она острее, чем рыбья кость, и светлее чем звездный луч

[Кенжеев, 2000, с. 142].
Первая строфа - 2 предложения, вторая третье предложение и начало четвертого, которое размещается на трех строфах. Такое разделение не случайно. Читатель вслед за автором постепенно переходит от общего плана к частному. Лирическое «Я» появляется в четвертом предложении - заключительном и самом объемном.

Первая фраза вызывает ассоциации со знаменитой сказкой о спящей красавице. Перед нами не просто покойники, а пострадавшие от злого заклятия завистливой ведьмы, уснувшие, ждущие своего часа. Таким образом, бытийное сообщение об умерших друзьях приобретает метафорическое значение. Следующее предложение, тесно связанное по смыслу с первым, синтаксически выделено, здесь на первый план выступает фигура Иисуса Христа. Обращение к созвездиям и фигуре Мессии, равно как и ряд умерших друзей поэта, создает ощущение взгляда сверху. Это не только пространственная панорама, но и картина определенного времени, хотя никаких прямых упоминаний временных координат читатель здесь не увидит, однако первое предложение и отсылки к творчеству Мандельштама вписывают произведение в контекст советской истории.

Вторая строфа, по замечанию самого Кенжеева, содержит две цитаты из Мандельштама: в ночь с 16 на 17 мая 1934 во время обыска и ареста этого поэта за стеной, у его соседа Кирсанова, играла гавайская гитара. В стихотворении «zитарное трень да брень» - признак тоскующего соседа, который, возможно, переживает то же, что и лирический герой, но отделен от него стеной, что и в прямом смысле, и в переносном стена непонимания, молчания и страха, когда нет доверия ближнему своему и каждый сам за себя. Пространство произведения, начинающегося с широкой панорамы, постепенно сужается и замыкается: "Я один в дому». Мигрень, которая характеризуется в медицинских справочниках как неврологическое заболевание, в стихотворении Мандельштама отрицается: «Нет, не мигрень, - но подай карандашик ментоловый...» (1931), хотя можно отметить, что, по замечанию Ю. И. Левина, «происходит отталкивание от определенных предикатов - при одновременном их утверждении - в некотором смысле» [Левин, с. 59]. Леонид Киселев (1946-1968) в цикле «Осип Мандельштам. Злобная поэма» расширяет границы понятия, говоря о «поэтической мигрени», которая «великим бедствием / Осеняет мой народ» [Киселев]. Эта мигрень - синоним поэтического дара и дара пророчества. У Кенжеева мигрень сравнивается с зимней мухой, явлением противоестественным и, по старинным поверьям, 
предвещающим болезнь или даже уход из жизни кого-то из домочадцев.

Водная стихия, заявленная еще в первой строке (рыбак, волнующаяся вода), проявляется снова в третьей строфе. Метафора «ночной улов» символизирует написанные произведения, которые автор, словно ремесленник, остающийся в тени, отдает перекупщику. Об этой скрытости и потаенности творчества говорит и глагол «npumux». При этом автор отстраняется практически полностью, впадает в некое забытье: «я не помню, сколько их было, слов, и рифмованных и проcmblx».

Если в первой строфе водная стихия ассоциируется с мировым Спасителем и жизнью вообще, в третьей - с бессознательным, которое практически невозможно добыть человеку, но доступно поэту, то в четвертой строфе символика рыбы, вбирающая в себя множество разнообразных смыслов, приобретает отрицательное значение: молчание, помеха, от которой сложно избавиться, а именно - острая рыбья кость.

Основные эмоции стихотворения - тоска, грусть и злость. Градация данных чувств завершается невозможностью избавиться от острой и светлой злости. Последняя строка (соединение водной и воздушной стихий) отрывает нас от личной трагедии и возвращает ко взгляду сверху, расширяя границы и показывая, что переживания лирического героя - не частный, не единичный случай.

В 2012 году из печати выходит книга Кенжеева «Сообщение», где наряду с новыми стихотворениями и тщательно отобранными произведениями прошлых лет опубликованы и стихи мальчика Теодора.

В творческой манере Теодора просматривается следование традициям обэриутов, которые пропагандировали «детский» взгляд на мир, то есть свежий и игровой подход к вещам и явлениям, выражающийся с помощью пародийности и поэтики абсурда. Обэриуты из-за нападок официальной критики вынужденно переместились в область детской литературы; Кенжеев делает следующий шаг и выпускает из печати стихотворения, «автор» которых ребенок - одиннадцатилетний мальчик Теодор.

Критики отмечают «недетский» взгляд Теодора на некоторые жизненные явления и присутствие в его лексиконе таких слов, которых одиннадцатилетний ребенок просто не может знать, упрекая поэта в недостаточно правдоподобно разыгранной мистификации. Однако маски Кенжееву нужны не для мистификаций и игр с читателями. Тонкий лирик, Кенжеев надевает маски, чтобы преодолеть трагичность и абсурдность жизни, поскольку сам же и заявляет, что для этого существует два способа - писать смешные или абсурдные стихи [Вдали мерцает город Галич, 2006].

Необычный синтаксис Теодора, отсутствие пунктуации, неожиданно возникающие образы порождают возможность неоднозначной интерпретации стихотворений.

Стихотворение «Отрада вольного улова...» перекликается с проанализированным произведением Кенжеева не только темой, но и обращением к водной и воздушной стихиям:

отрада вольного улова

веселый складывать слова

положим за день только слово

бывает за ночь три и два $<\ldots>$

[Кенжеев, 2012, с. 529].

Однако если у Кенжеева «ночной улов» отдается перекупщику, то у Теодора «вольнылй улов», который приносит не «мигрень», а «отраду», о чем также говорит прилагательное «весельій» в следующей строке. И в том, и в другом стихотворениях время творчества - ночь, но если лирический герой стихотворения Кенжеева не помнит «сколько их было, слов, и рифмованных и nростых», грустит и злится, то Теодор, несмотря на то что «положим за день только слово / бывает за ночь три и два» [Там же], счастлив, потому что муки творчества лучше «окаменения», ведь «мертвоед < .. > бывает что и жизнью изелой / ни хорды не произнесет» [Там же]. Употребление математического и биологического термина «хорда» говорит о том, что «мертвоед» не только «прямого» слова не произносит, не говоря уже о поэтических, но и даже живет «искривленно». Следующие строчки стихотворения графически отделены, однако продолжают ту же мысль. «Окаменелость» и «мертвенность» может привести к тому, что, даже обладая всем необходимым (необычное на первый взгляд словосочетание «хоть сквозь хрустальну чечевицу» легко поддается расшифровке: так в научных кругах называли хрусталик, то есть речь идет о зрении), можно «проморгать» жизнь. Более того, в таком случае лишаешься не только права участия, но и «титула очевидца».

Третья строфа выводит читателя на обобщенный культурный уровень. Во-первых, здесь появляется термин homo ludens, что отсылает нас к знаменитому труду Йохана Хейзинги. Вовторых, упоминается Замоскворечье - район Москвы с очень богатой поэтической историей. Втретьих, возникает фамилия Ницше. Оба филоcoфа, и Хейзинга, и Ницше, занимались вопросами культуры. «Человека играющего» у Теодо- 
ра сопровождает прилагательное «неразумныцй, а следующая строчка («стучись $и$ я к тебе прильну») вызывает ассоциации со знаменитым евангельским «стучите - и вам откроют», тем самым поднимая говорящего (разумеется, поэта) выше обычного человека, ближе к Богу. По Замоскворечью, вскормившему многих литераторов, бродит беззубый, а значит, не способный нападать и защищаться, зверь. Вполне обоснованно будет предположить, что этот зверь олицетворяет писателя, задавленного эпохой, затравленного и потерянного. Неожиданно сравнение замоскворецкого зверя с Ницше, который так же воет на луну. Но если мы вспомним, что вой на луну отождествляется с глубокой тоской, а именно Фридриху Ницше принадлежит мысль, что чем выше культура человека, тем менее счастливым он себя чувствует, то все становится на свои места.

Завершается стихотворение невероятным по красоте образом: «как бы любовное письмо / прочтя спит мачеха творений / земных ...» [Там же]. Если рассматривать оппозиции мать / мачеха и земное / небесное, то можно предположить, что «мачеха земных творений» принадлежит «небесной», божественной сфере. Тогда эта фигура может расшифровываться как муза, поэзия, творчество вообще. Изначальное напряжение заключительной строфы, о котором свидетельствует строчка «и на излете волчьих трелей», где наречие указывает на кульминационную фазу перед окончанием, падением, а оксюморон «волчья трель» добавляет вибрацию и скорость, сменяется нежностью, романтичностью («как бы любовное письмо / прочтя») и умиротворением («и видит сньл быть мо»).

В целом «мерцающее» и образное стихотворение Теодора наполнено радостью, потому что даже муки творчества приносят счастье боговдохновенному поэту, и способность «складывать слова» он бы не променял на спокойную, но «окаменелую» жизнь.

Произведений Ремонта Приборова, посвященных тематике поэта и поэзии, не очень много, и в большинстве они представляют послания (например, «Экономическое послание Тимуру Кибирову в связи с его сетованиями на бедность и невозможность продать плоды своей музы в условиях рынка (писано от лица того же Б. Кенжеева)» или «Патриотическое послание Сергею Гандлевскому, содержащее краткие инструкции по сочинению литературы в период после падения коммунизма»).

В данных стихотворениях на первый план выдвигается утилитарная функция поэзии: «Хозяйственника дар / прекрасней, чем Егор Гайдар,
/ пленительней утех любовных» [Приборов, с. 28]. Приборов заявляет, что стране не нужны «лирические вздохи», призывает: «Для Агрохима с Кредобанком / хореи звучные найди» [Там же]. Писать, по его мнению, необходимо о фермах, нерентабельности колхозов, денежных реформах и других насущных проблемах страны, а сам поэт должен быть изобретательным и хватким, думать о меценатах («Не спорю я - презренно злато. / Но разве лирнику к лииу / отвергнуть милость Мецената / благословенному певцу?» [Там же]) или где-то служить («Чем всуе рассуждать о девстве музы милой, / пой небо звездное, от музыки дрожи, / друзей не обижай и сердияа не насилуй - / но днем, советую, хоть где-нибудь служи» [Там же, с. 34]).

В этом ряду несколько выделяется «Метафорическое стихотворение о поэтическом призвании». Приборов отказывается от ясности в пользу метафоры и сравнивает поэтическое творчество со смолой. Впрочем, данное неожиданное сравнение также в духе Приборова: «Смола продукт зело полезный» [Там же, с. 169], равно как и «неповторимый дар» [Там же] поэта. Неслучайно появляется сопоставление смолы с кровью. В литературной традиции кровь ассоциируется с жизненной энергией (например, выражение «горячая кровь» означает пылкий и страстный темперамент). Приборов же между темпераментностью, чувствительностью и спокойствием, сдержанностью выбирает второе, ведь «жаркий яд пылающего чувства» так или иначе отравляет душу.

Приборов мечтает, чтобы его стихи «превратились в золотой янтарь, / с душой внутри, как некой древней пчелкой!» [Там же], то есть были бы не только прекрасны в своей ясности и осмысленности, но и полезны.

Произведения Кенжеева, Приборова и Теодора, объединенные тематически, значительно отличаются друг от друга в интерпретации поэтического признания, а также на формальном уровне. Наблюдается ироническое растроен и е, когда важные для лирики Кенжеева темы подвергаются шутовскому низвержению у квасного патриота Приборова и превращаются в наивно-идиотическую бессмыслицу у Теодора. Гротескность масок, нарочитая «выпуклость» их характерных черт реализуют литературную игру. Кенжеев выходит за рамки лирики, при этом желая сохранить собственное «лицо». Доверяя «авторство» маскам, поэт сохраняет собственную идентичность и расширяет границы своего творчества, наполняя его новым звучанием. В содержательном плане наивно-восторженный взгляд на поэтическое творчество у Теодора и прямой, 
утилитарный подход у Приборова контрастируют с мироощущением лирического героя Кенжеева. Разные грани поэтического творчества, представленные данными масками, обобщаются и синтезируются в произведениях самого автора, приобретая значение прекрасного и мучительного дара, поскольку поэт не может не писать, для него это способ прикоснуться в высшему, божественному и сделать, как минимум, свою жизнь счастливее. Таким образом, маски Бахыта Кенжеева, с помощью которых поэт моделирует различные игровые поэтики, «примеряя» на себя иные поэтические манеры, не только помогают ему преодолеть абсурдность и трагичность жизни, но и ярче раскрывают его собственную лирику.

\section{Список литературы}

Вдали мерцает город Галич. Стихи мальчика Теодора / Вступительное слово и публикация Бахыта Кенжеева // Новый мир. 2006. № 7 URL: http://magazines.russ.ru/novyi_mi/2006/7/teo7.html (дата обращения: 11.08.2018)

Кенжеев Б. Ш. Сообщение. М.: Эксмо, 2012. $536 \mathrm{c}$.

Кенжеев Бахыт. Из семи книг: Стихотворения. М.: изд-во «Независимая газета», 2000. 265 с.

Киселев Л. Стихотворения разных лет // Vilavi.ru: «Солнечный ветер» - историко-художественный журнал для всех, 2019. URL: http://www.vilavi.ru/ $\mathrm{raz} / \mathrm{kis} / \mathrm{kis} 2 . \mathrm{shtml}$ (дата обращения: 11.02.2019)

Левин Ю. И. Избранные труды. Поэтика. Семиотика. М.: Язык русской культуры, 1998. 824 с.

Левицкая Л. В. Маска и лицо в русском искусстве конца 19 начала 20 веков: автореф. дис. ... канд. искусствоведения. М., 2001. 152 с. URL: http://www.dissercat.com/content/maska-i-litso-vrusskom-iskusstve-kontsa-19-nachala-20-vekov (дата обращения: 11.02.2019)

Осьмухина О. Ю. Авторская маска в русской прозе 1760-1830-х гг.: автореф. дисс. ... докт филол. наук. Саранск: изд-во МГПИ, 2009. 40 с.
Приборов Р. Гражданская лирика и другие сочинения. 1969-2013 / Ремонт Приборов. М.: ОГИ, 2014. $264 \mathrm{c}$.

\section{References}

Kenzheev, B. Sh. (2012). Soobshchenie [A Message]. 536 p. Moscow, Eksmo. (In Russian)

Kenzheev, Bakhyt. (2000). Iz semi knig: Stikhotvoreniia [Of the Seven Books: Poems]. 265 p. Moscow, izd-vo "Nezavisimaia gazeta". (In Russian)

Kiselev, L. (2019). Stikhotvoreniia raznykh let [Poems of Different Years]. Vilavi.ru: "Solnechnyi veter" istoriko-khudozhestvennyi zhurnal dlia vsekh. URL: http://www.vilavi.ru/raz/kis/kis2.shtml (accessed: 11.02.2019). (In Russian)

Levin, Iu. I. (1998). Izbrannye trudy. Poetika. Semiotika [Selected Works. Poetics. Semiotics]. 824 p. Moscow, Iazyk russkoi kul'tury. (In Russian)

Levitskaia, L. V. (2001). Maska $i$ litso v russkom iskusstve kontsa 19 nachala 20 vekov: avtoref. dis. ... kand. iskusstvovedeniia [The Mask and the Face in Russian Art of the Late 19th and Early 20th Centuries: Ph.D. Thesis]. 152 p. Moscow. URL: http://www.dissercat.com/ content/maska-i-litso-v-russkom-iskusstve-kontsa-19nachala-20-vekov (accessed: 11.02.2019). (In Russian)

Os'mukhina, O. Iu. (2009). Avtorskaia maska v russkoi proze 1760-1830-kh gg.: avtoref. diss. ... dokt filol. nauk [Authorial Mask in Russian Prose of the 17601830s: Doctoral Thesis Abstract]. Saransk, izd-vo MGPI, 40 p. (In Russian)

Priborov, R. (2014). Grazhdanskaia lirika i drugie sochineniia [Civil Lyrical Works and Other Writings]. 1969-2013. Remont Priborov. 264 p. Moscow, OGI. (In Russian)

Vdali mertsaet gorod Galich. Stikhi mal'chika Teodora (2006) [Far Away the City of Galich Flickers. Poems by Theodore Boy]. Vstupitel'noe slovo i publikatsiia Bakhyta Kenzheeva. Novyi mir. No. 7. URL: http://magazines.russ.ru/novyi_mi/2006/7/teo7.html (accessed: 11.02.2019). (In Russian)

The article was submitted on 13.03.2019

Поступила в редакцию 13.03.2019

\section{Arnautova Viktoria Valerievna,}

graduate student,

Kazan Federal University,

18 Kremlyovskaya Str.,

Kazan, 420008, Russian Federation.

ewich.2793@yandex.ru 